\section{International Scientific Journal Theoretical \& Applied Science}

p-ISSN: 2308-4944 (print) e-ISSN: 2409-0085 (online)

Year: 2017 Issue: $05 \quad$ Volume: 49

Published: 3.05.2017 http://T-Science.org

SECTION 7. Mechanics and machine construction.
Vadim Anatolyevich Gulyaev Associate Professor of the Department «Equipment and technology of machine-building production»» FSBEI HPE «Togliatti State University», Russia Colmy@tltsu.ru

Nikolay Yuryevich Loginov Associate Professor of the Department «Equipment and technology of machine-building production» FSBEI HPE «Togliatti State University», Russia

\title{
ASSESSMENT OF THE RELEVANCE OF QUALITY ASSURANCE SYSTEMS OF THE REARVIEW MIRRORS BASED ON ISHIKAWA DIAGRAMS
}

Abstract: In this article we describe relevance of creation of system of the automated contactless control of optical defects of automobile rear-view mirrors is considered.

Key words: contactless control, automobile mirrors, control of defects, Isikava's chart.

Language: Russian

Citation: Gulyaev VA, Loginov NY (2017) ASSESSMENT OF THE RELEVANCE OF QUALITY ASSURANCE SYSTEMS OF THE REARVIEW MIRRORS BASED ON ISHIKAWA DIAGRAMS. ISJ Theoretical \& Applied Science, 05 (49): 21-23.

Soi: http://s-o-i.org/1.1/TAS-05-49-4 Doi: crossef https://dx.doi.org/10.15863/TAS.2017.05.49.4

\section{ОЦЕНКА АКТУАЛЬНОСТИ СИСТЕМ КОНТРОЛЯ КАЧЕСТВА ЗЕРКАЛ ЗАДНЕГО ВИДА АВТОМОБИЛЯ НА ОСНОВЕ ДИАГРАММЫ ИСИКАВЫ}

Аннотация: В статье рассматривается актуальность создания системы автоматизированного бесконтактного контроля оптических дефектов автомобильных зеркал заднего вида.

Ключевые слова: бесконтактный контроль, автомобильные зеркала, контроль дефектов, диаграмма Исикавы.

\section{Introduction}

Обеспечение безопасности движения автомобиля задача многофакторная. Одним из элементов безопасности являются зеркала заднего вида автомобиля. Передача информации водителю об обстановке на дороге осуществляется оптическим элементом. Он представляет собой зеркальное стекло с отражающим покрытием называемым амальгамой. Любой дефект, как на поверхности стекла, так и на амальгаме может ухудшить видимость, значительно увеличить «мертвую» зону и привести к серьезным последствиям.

\section{Materials and Methods}

Количество дефектов, встречающихся на практике достаточно велико. К наиболее часто встречаемым и опасным дефектам можно отнести [1] пороки стекломассы (пузыри, мошка, свиль), пороки формования (отпечатки валков, прилипшая крошка), пороки вызванные механическими повреждениями (царапины, потертость, скол, выступ, трещигна, посечка) и прочие пороки (выщелачивание, дросс, блюм). Стекло оптического элемента не должно иметь указанных выше дефектов. Однако, стоит отметить, что ряд дефектов, таких как, незначительные единичные царапины, в краевой области зеркала не являются дефектами и допускаются стандартами. Это связано с тем, что эти области либо не видны с места водителя, либо не несут существенной информации. Данные области обозначены светлым зеленым цветом на рисунке 1 .

Выявление основных факторов, которые могут повлиять на качество зеркала поведем путем построения и анализа диаграммы Исикавы [2].

Для этого выявляем и систематизируем все причин, каким-либо образом влияющие на наличие дефектов на зеркале. Затем группируем эти причины в зависимости от смысловых и причинно-следственных связей между ними. Определяем значимость причины внутри каждого блока и анализируем получившийся результат. 


\begin{tabular}{l|lrl|lll} 
& ISRA (India) & $=\mathbf{1 . 3 4 4}$ & SIS (USA) & $=\mathbf{0 . 9 1 2}$ & ICV (Poland) & $=\mathbf{6 . 6 3 0}$ \\
Impact Factor: & ISI (Dubai, UAE) $=\mathbf{0 . 8 2 9}$ & PUHЦ (Russia) & $=\mathbf{0 . 2 3 4}$ & PIF (India) & $=\mathbf{1 . 9 4 0}$ \\
& GIF (Australia) & $\mathbf{0 . 5 6 4}$ & ESJI (KZ) & $=\mathbf{3 . 8 6 0}$ & IBI (India) & $=\mathbf{4 . 2 6 0}$ \\
& JIF & $\mathbf{1 . 5 0 0}$ & SJIF (Morocco) & $\mathbf{2 . 0 3 1}$ & & \\
\hline
\end{tabular}

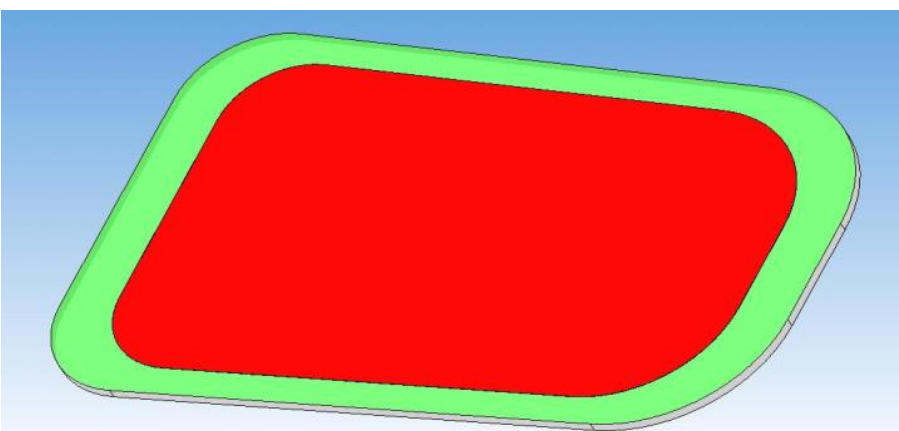

$\kappa^{*}$

Рисунок1 - Области зеркала.

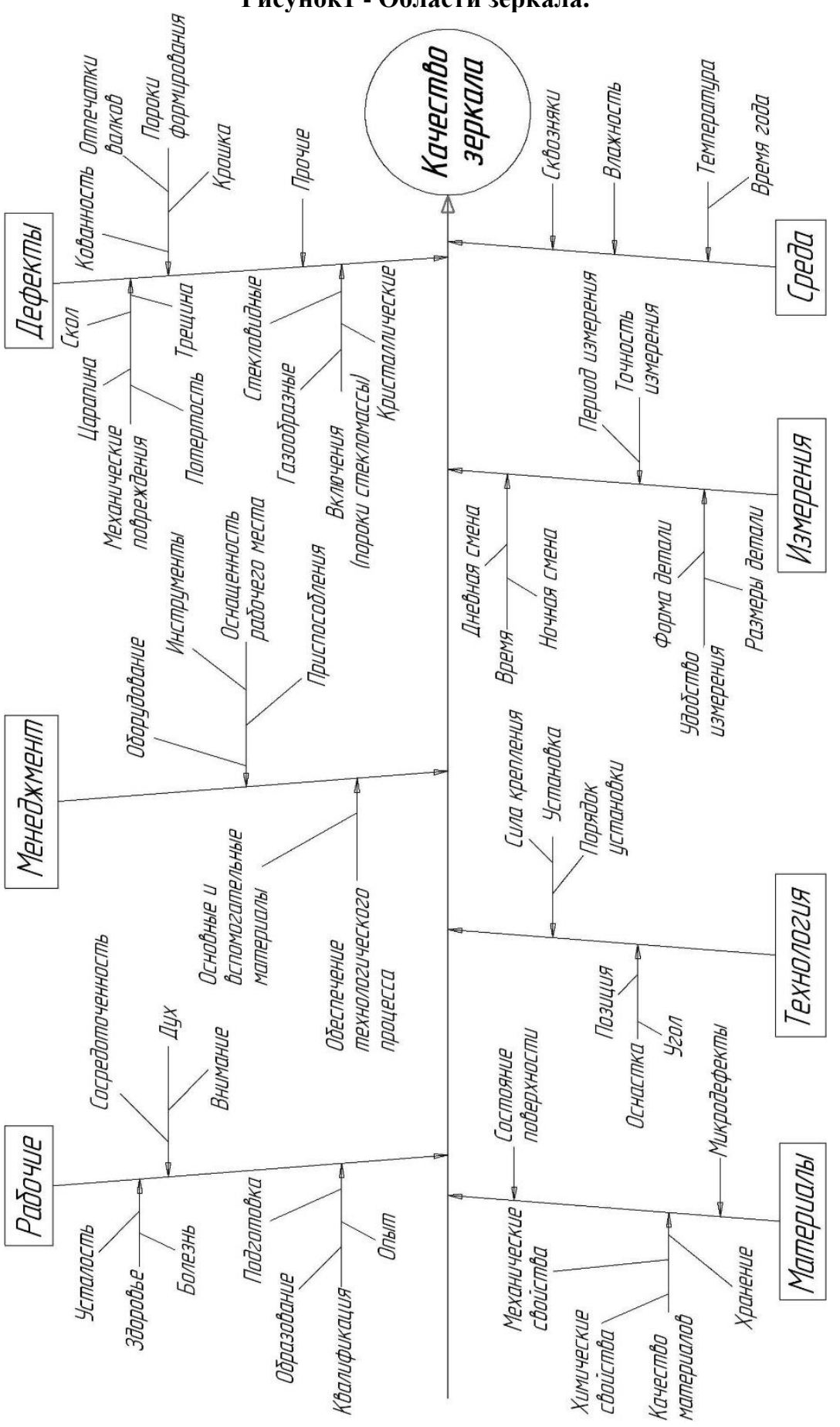

Рисунок 2 - Диаграмма Исикавы. 
К факторам верхнего ранга отнесем: материалы, технологию производства, измерения и контроль, окружающая среда, рабочие и персонал, менеджмент, дефекты. К факторам второго ранга, влияющим на соответствующие факторы первого ранга, отнесем: время измерения, удобство, точность и т.д. Затем определяем факторы третьего ранга, влияющие на факторы второго ранга. Полученная диаграмма представлена на рисунке 2.

Из анализа построенной диаграммы можно сделать вывод о том, что большинство факторов влияющих на качество зеркал могут быть устранены при проведении контроля. Однако, сам процесс контроля также может влиять на качество [3].

Одной из основных причин влияния процесса контроля на его качество является человеческий фактор. Это связано с тем, что чаще всего контроль проводится человеком без применения специальных средств [4]. Из построенной диаграммы следует, что это приводит к появлению субъективных факторов связанных с индивидуальными особенностями человека.

\section{Conclusion}

Проведенный анализ диаграммы показал необходимость автоматизации процесса контроля зеркал заднего вида автомобиля. Данное решение исключит множество факторов всех рангов влияющих на качество зеркала. Однако, следует отметить, что решение данной проблемы весьма сложная задача. Для ее решения создание систем подобных уже известным [5, 6]. При этом ключевым вопросом при разработке данной системы будет обработка полученной информации. Для этого также можно использовать уже известные решения $[7,8,9$, $10]$.

\section{References:}

1. Zhilin AA, Soldatov AA, Guljaev VA (2004) Dinamicheskoe nagruzhenie kak metod ocenki dopustimyh vnutrennih naprjazhenij termoobrabotannyh opticheski aktivnyh jelementov // Izvestija Volgogradskogo gosudarstvennogo tehnicheskogo universiteta. 2004. №1. p. 35-36.

2. (2009) Osnovy rascheta i proektirovanija sistem avtomaticheskogo upravlenija v mashinostroenii: Ucheb. posobie / O.I. Drachev, D.A. Rastorguev, A.A. Soldatov, A.G. Shirtladze - Staryj Oskol.

3. Soldatov AA, Guljaev VA, Zhilin AA, Belous DV (2004) Razrabotka avtomatizirovannoj sistemy beskontaktnogo kontrolja geometricheskih parametrov kuzova avtomobilja // Izvestija Volgogradskogo gosudarstvennogo tehnicheskogo universiteta. 2004. №1. p. 46-48.

4. Kozlov AA (2005) Povyshenie kachestva kontrolja zazorov kuzova avtomobilja putem avtomatizacii processa/A.A. Kozlov avtoreferat dissertacii na soiskanie uchenoj stepeni kandidata tehnicheskih nauk/Moskovskij gosudarstvennyj tehnologicheskij universitet. Tol'jatti.

5. Kozlov AA (2005) Povyshenie kachestva kontrolja zazorov kuzova avtomobilja putem avtomatizacii processa/A.A. Kozlov dissertacija na soiskanie uchenoj stepeni kandidata tehnicheskih nauk/Tol'jatti.
6. Kozlov AA (2015) Jekspress-analiz mikrotopografii poverhnosti pri plakirovanii gibkim instrumentom // V sbornike: Teplofizicheskie i tehnologicheskie aspekty povyshenija jeffektivnosti mashinostroitel'nogo proizvodstva Trudy IV mezhdunarodnoj nauchno-tehnicheskoj konferencii (Reznikovskie chtenija). 2015. p. 261-264

7. Kozlov A, Valentiev V (2013) Detection of defects by the Otsu method at control of automobile rear-vew mirrors / Kozlov A., Valentiev V. -V sbornike: PRESSING ISSUES AND PRIORITIES IN DEVELOPMENT OF THE SCIENTIFIC AND TECHNOLOGICAL COMPLEX B\&M Publishing Research and Publishing Center «Colloquium»; Science editor: A. Burkov. San Francisco, California, USA, 2013. p. 109-112.

8. Gordeev AV, Loginov NJ (2015) Optimizacija tehnicheskih parametrov pri reshenii inzhenernyh zadach // Vektor nauki Tol'jattinskogo gosudarstvennogo universiteta. 2015. №4 (34). p. 25-30.

9. Gruzman IS (2002) Cifrovaja obrabotka izobrazhenij v informacionnyh sistemah: Ucheb.posobie / I.S. Gruzman, V.S. Kirichuk, V.P. Kosyh - Novosibirsk: Izd-vo NGTU, 2002.-352 p.

10. Otsu N (1979) A Threshold Selection Method from Gray-Level Histograms, IEEE Transactions on Systems, Man, and Cybernetics, Vol. 9, No. 1, 1979, p. 62-66. 